\title{
Desynchronizing Plasmodium Cell Cycle Increases Chloroquine Protection at Suboptimal Doses
}

\author{
Piero Bagnaresi ${ }^{1}$, Regina P. Markus ${ }^{1}$, Carlos T. Hotta ${ }^{1}$, Tulio Pozzan ${ }^{2}$ and Célia R.S. Garcia*,1 \\ ${ }^{I}$ Departamento de Fisiologia, Instituto de Biociências, Universidade de São Paulo, São Paulo, Brazil \\ ${ }^{2}$ Department of Biomedical Sciences, Viale G. Colombo 3, 35121 Padua, Italy
}

\begin{abstract}
We have previously shown that in vivo and in vitro the hormone melatonin is responsible for the synchronous development of Plasmodia. Melatonin can also mobilize calcium from internal stores in these parasites and this response is abolished by luzindole, a melatonin antagonist. We here demonstrate that in vivo alteration of parasite synchronous development, using luzindole, partially improves survival of infected mice and dramatically increases the antimalarial activity of chloroquine. The data presented may lead to a conceptually new paradigm for malaria infection therapy and provide novel evidence suggesting that the malaria parasite uses the cell cycle synchrony as one of the strategies to evade the host immune system.
\end{abstract}

Keywords: Malaria, Plasmodium, Rhythm, Chloroquine.

\section{INTRODUCTION}

Malaria is still the major cause of death in the world. Recent estimates [1] show that Plasmodium falciparum infection still affects 515 millions of human beings, and more than 2 billions people are at risk. This number is $50 \%$ bigger than the last WHO estimates. In Africa, continent that is most impaired by the burden, severe malaria causes $10 \%$ maternal mortality [2], and malaria is the main cause of children death in Angola [3] Though effective antimalarial therapies are available since a long time, not only the employed drugs have important toxic side effects, but over the last years Plasmodia strains resistant to classical treatments have evolved $[4,5]$.

The parasite has a complex life cycle, involving a vertebrate and a invertebrate host. In human malaria, the Anopheles mosquito bite delivers infective sporozoites forms that are taken by lymphatic and blood circulation [6], and reach the liver, where they invade the hepatocytes and mature into merozoites, which go back into circulation in a very particular fashion [7], avoiding the host immune system in the liver sinusoids. These forms are infective to the circulating red blood cells (RBC) (for review, see [8]). Once invaded, these RBCs are highly modified by the parasite, due to intense protein trafficking [9].

One of the most striking features of malaria in humans is its circadian rhythm, as revealed by the regularity of fever peaks, which occur with intervals multiple of 24 hours and are related to the synchronous development of the parasites within red blood cells, RBC, and the paroxystic release of pyrogens. This in turn depends on the fact that the processes of erythrocyte rupture and new cell invasion is highly synchronous [10].

*Address correspondence to this author at the Rua do Matão, travessa 14, n. 321. Cidade Universitária, São Paulo, Brazil, 05508-900;

Tel: +55(11)30917518; Fax: +55(11)30918095; E-mail: cgarcia@usp.br
We have shown that the hormone melatonin, a known circadian marker [11] is able to synchronize the life cycle of $P$. chabaudi and $P$. falciparum in vitro and this effect is abolished by luzindole, a melatonin receptor antagonist [12]. The synchronism is also lost in vivo in pinealectomized mice (restored by melatonin administration) and upon injection in the animal of luzindole, a melatonin receptor antagonist [12].

As to the molecular mechanism of melatonin action in the parasites we have shown that melatonin can elicit an increase in intracellular calcium concentration $\left(\left[\mathrm{Ca}^{2+}\right]_{\mathrm{i}}\right)$ in Plasmodium trophozoites [12, 13]. A great number of articles shows the importance of calcium signaling in these parasites [12-24]. In addition, in Plasmodium falciparum, we have demonstrated that the melatonin-signaling pathway involves a complex crosstalk between $\mathrm{Ca}^{2+}$ and cAMP [15], and further activation of PKA. Proteins kinases are key components in Plasmodium signaling pathways [25-27], as other components of transduction pathways, such as proteases [28], which could configure new targets to chemotherapy $[29,30]$.

In this report we addressed the problem of the evolutionary role of synchronicity by the following approach: using the murine strain $P$. chabaudi we have tested in the live mice whether Plasmodia cell cycle desynchronization has any beneficial effects on the development of the disease. The data demonstrate that in vivo desynchronization with luzindole has a small, but detectable protective effect against Plasmodium toxicity, and most important it dramatically synergizes with classical antimalarial drug in protecting the animal from the infection.

\section{MATERIAL AND METHODS}

\section{Parasites}

P. chabaudi (strain AJ, clone FIP-Pc1) was maintained in $\mathrm{Balb} / \mathrm{C}$ mice by transfer of infection The procedure for collecting blood and removing platelets has been described previously by Hotta et al. 2000 [12]. 


\section{In Vivo Experiments with $P$. chabaudi}

$\mathrm{Balb} / \mathrm{C}$ mice were infected with $10^{7}$ parasites in a photoperiodic regime (12hr light / $12 \mathrm{hr}$ dark) at day 0 . Chloroquine $(1 \mathrm{mg} / \mathrm{Kg}, 1,5 \mathrm{mg} / \mathrm{kg}, 2 \mathrm{mg} / \mathrm{Kg}$ and $3 \mathrm{mg} / \mathrm{Kg}$ i.p) was administered at zeitgeber time 6 (ZT6) and luzindole at ZT12 $(15 \mathrm{mg} / \mathrm{kg}$ i.p.) (ZT0 corresponds to the beginning of the light phase of the daily cycle). The treatment with choroquine and luzindole started simultaneously. Chloroquine was kept in PBS and Luzindole was diluted in $2 \%$ ETOH immediately before administration. On each day, at ZT11, blood samples were collected from tail blood to access parasitemia by counting no less than 1000 cells in Giemsastained blood smears. The survival rate was measured at ZT0 and ZT12.

\section{RESULTS}

\section{Desynchronizing Plasmodium Cell Cycle Enhances the Protective Effect of Chloroquine In Vivo}

Infection with $P$. chabaudi in mice is highly toxic. As shown in Fig. (1), when Balb/C mice were injected with $10^{7}$ parasites, all animals were dead in 7 days. On the contrary, all animal survived the infection when they were treated with $3 \mathrm{mg} / \mathrm{Kg}$ of the classical antimalarial drug chloroquine. In Fig. (1), the protective effect of different doses of chloroquine on animal survival was also tested. The dose response is relatively sharp, with no protection at $1 \mathrm{mg} / \mathrm{Kg}$ and complete protection by $3 \mathrm{mg} / \mathrm{Kg}$.

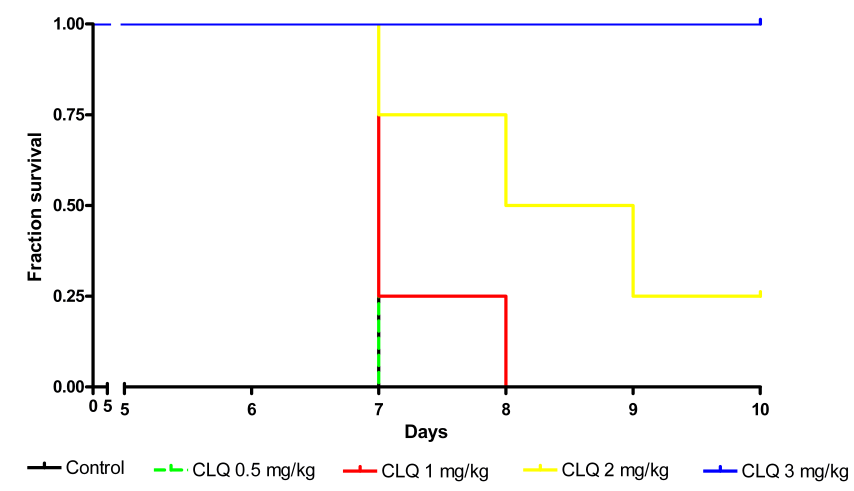

Fig. (1). Chloroquine effect on $P$. chabaudi infected animal survival. Balb/C mice were infected with at day 0 with $10^{7}$ parasites in a photoperiodic regime (12hr light / $12 \mathrm{hr}$ dark). Chloroquine (CLQ) was administered at zeitgeber time (ZT) 6. The survival rate was measured everyday, at ZT0 and ZT12. The curves are significally different by Logrank test $(\mathrm{P}=0.0006)$.

In order to test whether Plasmodia synchronous development played a role in the development of the infection, in the experiment presented in Fig. (2), the animals were in- jected together with the parasites with the melatonin antagonist luzindole $(15 \mathrm{mg} / \mathrm{Kg})$. The treatment with luzindole continued throughout the duration of the experiments with one injection per day (see Methods). The luzindole treatment resulted in a modest, yet significant protection of the animals from the deadly effect of the parasites, in as much as $20 \%$ of the animals survived at day 10 , i.e. at a time where all controls treated with vector alone were dead. In order to further test whether this protective effect of luzindole could represent an additional therapeutic strategy to combat Plasmodium infection we tested whether luzindole treatment could act synergistically with suboptimal doses of chloroquine. As shown in Fig. (2), subobtimal dose of chloroquine $(1.5 \mathrm{mg} / \mathrm{Kg})$ resulted in a small, yet significant, reduction in animal mortality, especially in the first 6 days of treatment. Strikingly, injection of the suboptimal chloroquine dose (1.5 $\mathrm{mg} / \mathrm{kg})$ and luzindole $(15 \mathrm{mg} / \mathrm{kg})$ strongly inhibited mice mortality, with over $70 \%$ of the animals still alive at day 10 .

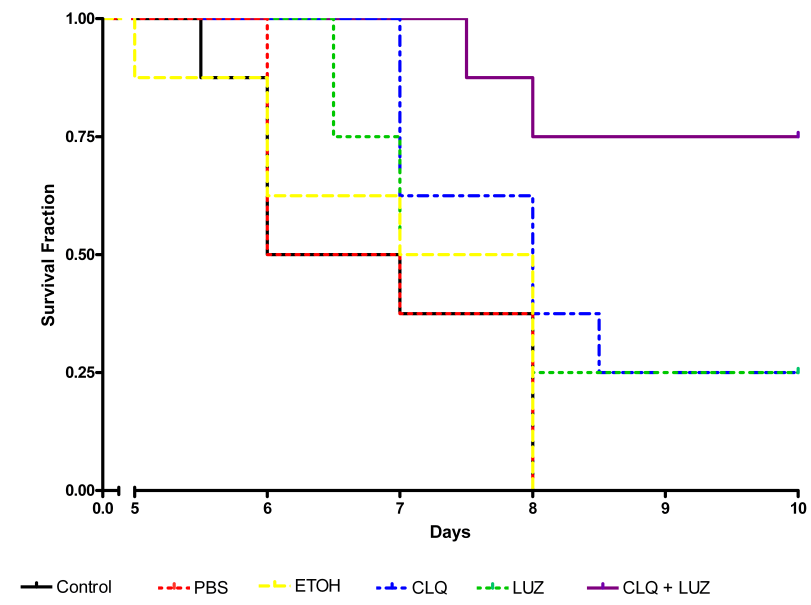

Fig. (2). Survival of Balc/C mice after infection with $P$. chabaudi. $\mathrm{Balb} / \mathrm{C}$ mice were infected at day 0 with $10^{7}$ parasites in a photoperiodic regime (12hr light / $12 \mathrm{hr}$ dark). Chloroquine was administered at zeitgeber time 6 (ZT6) and luzindole at ZT12 (ZT0 corresponds to the beginning of the light phase of the daily cycle). Every day of the experiment, at ZT11, blood samples were collected from tail blood, and parasitemia was counted on Giemsastained smears. Where indicated the animals were also injected with $1.5 \mathrm{mg} / \mathrm{kg}$ Chloroquine (CLQ) and/or $15 \mathrm{mg} / \mathrm{kg}$ Luzindole (LUZ), solvent alone (PBS or ethanol) or no addition (control). 8 animals per group. Typical experiment of three independent trials. The survival rate was measured at ZT0 and ZT12. The curves are different controls with statistical significance by Logrank test $(\mathrm{P}=0.002)$.

In order to verify whether luzindole treatment, alone or in combination with chloroquine, exerted its protective effect by reducing the amount of infected cells, parasitemia was measured by counting Giemsa-stained smears 4 days after

Table 1. In vivo parasitemia measured at day 4. Mean of 8 animals. Typical experiment of three independent trials. The parasitemias are statistically different from each other by 1-way ANOVA variance test and Newman-Keuls post test $(P<$ 0.0001), except for the pair CLQ $3 \mathrm{mg} / \mathrm{Kg}$ vs LUZ $15 \mathrm{mg} / \mathrm{Kg}+$ CLQ $1.5 \mathrm{mg} / \mathrm{Kg}$

\begin{tabular}{|c|c|c|c|c|c|}
\hline Treatment & Control & CLQ 1.5 mg/kg & LUZ 15 mg/kg & CLQ 3 mg/kg & LUZ 15 mg/kg CLQ 1.5 mg/kg \\
\hline \hline Parasitemia & $45.75 \pm 2.04$ & $32.63 \pm 0.89$ & $38.61 \pm 1.6$ & $3.20 \pm 0.08$ & $3.62 \pm 0.13$ \\
\hline
\end{tabular}


injection of the parasites (Table 1). Mice treated with optimal doses of chloroquine or luzindole + chloroquine (at suboptimal doses) had a drastic reduction in the number of intraerythrocyte parasites. Luzindole and suboptimal doses of chloroquine, when given separately, were not able to significantly inhibit the number of infected cells.

\section{DISCUSSION}

The rhythmicity of Plasmodia infection, its most distinctive trait, has been studied since the beginning of the $\mathrm{XX}$ century (for review, see Garcia et al. 2001). Attempts to take advantage of the periodicity of malaria infection have been made in the past, with little success $[31,32]$. However, this chronotherapeutic approach has been investigated in a vast number of diseases e.g. cancer, arthritis, heart ischemia [3336], often with good therapeuthical outcomes. The understanding of the parasite's rhythm, and its modulation, could serve malaria treatment by, for instance, enabling the use of lower dosage of antimalarial to clear out the disease.

The question then arises as to the evolutionary advantage for the parasites provided by synchronization of their cell cycle by host produced melatonin. One possible hypothesis is that the synchronous maturation of the Plasmodia is a strategy to evade the immune system [12, 16, 19, 37]. Indeed when the parasites synchronously burst the RBCs, they flood the circulation with a huge number of merozoites, overcoming the capacity of the immune system to efficiently deal with the infection. The immune system does kill some parasites, but a sufficient number of merozoites can infect other RBCs, leading the infection to another intraerythocytic cycle, i.e. away from the host cellular and humoral defenses. Additional roles for synchronicity has been suggested, in particular concerning the efficiency of vector infection. Here we have readdressed the problem, by taking advantage of the demonstration that the rhythmic cycle of Plasmodia in vitro and in vivo depends on the hormone melatonin. The rationale of the approach is that alteration in the Plasmodia synchronicity may favor the capacity of the host defense system that could more efficiently deal with parasites asynchronously bursting the RBC than billions of parasites coming out of the red blood cells all at the same time. The in vivo experiments with mice infected with $P$. chabaudi clearly showed that the disruption of the rhythmicity of the Plasmodium cell cycle, using luzindol, a melatonin antagonist, has a small beneficial effect on animal survival. It has also been reported that luzindol act as antioxidant [38]. The more striking results, however, has been the discovery that luzindole drastically improves the therapeutic effect of a suboptimal dose of chloroquine. Indeed, the associated treatment of the animals with the melatonin antagonist and $1,5 \mathrm{mg} / \mathrm{Kg}$ of chloroquine, a dose that hardly affects animal survival on its own, has a clear synergistic effect on the survival of Balb/C mice. In particular, at day $10,25 \%$ of the animals treated with either luzindole or cloroquine alone survived, while $75 \%$ were still alive if treated with both drugs. The treatment with luzindole and cloroquine also decreases the parasitemia, measured on the fourth day of infection. It should be stressed that luzindole has no toxic effect on Plasmodia in vitro and thus the simplest explanation for its efficacy is that the host defense mechanisms become more effective when the burst of erythrocytes becomes asynchronous.
The current antimalarial drugs possess a large number of adverse effects, which are predominantly dose-dependent. By using a lower dose, combined with a desynchronizing agent, it is expected that these effects would be milder, making the treatment less toxic for the patient. The adverse effects include nausea, headache, pruritus. Toxic effects includes retinal, cardiovascular- hypotension, vasodilatation, arrhythmias, cardiac arrest - and neurological - convulsions and confusion - disorders. The chloroquine cardiovascular toxicity comes from its membrane stabilization properties, direct negative ionotrophic effects, arterial vasodilatation promotion and manifests as disturbances in cardiac rhythm and conductance, myocardiopathy or vasoplegic shocks [39]. Even in normal cases, when the dosage used in current chloroquine therapy is well tolerated by the patient, the concern with these adverse and toxic effects is always taken into account, whether for treatment or chemoprophylaxis.

In conclusion, we here demonstrate that a antagonist of melatonin, luzindole, while having some effects on its own on infected animal survival, is strongly synergistic with a classical antimalarial drug such as chloroquine. We suggest that the desynchronization of Plasmodia cell cycle by luzindole is beneficial because it allows the host defense mechanisms to more effectively combat the infection. The present data may be of practical significance. In particular, considering the toxicity of chloroquine (and of other antimalarial drugs) [40], the possibility to reduce the effective dose of these compounds by combining them with a drug such as a melatonin antagonist may represent a novel paradigm in malaria therapy and may turn out to be of advantage in the treatment of parasites that are becoming resistant to current therapies.

\section{ACKNOWLEDGEMENTS}

We thank Fundação de Amparo à pesquisa de São Paulo (Fapesp) for funding CRSG and RPM. We also thank $\mathrm{CNPq} / \mathrm{MS}$ Neglected Tropical Diseases Grant for funding CRSG. PB received fellowship from FAPESP. We thank Dr. Robert S. Desowitz for the critical review and helpful suggestions.

\section{REFERENCES}

[1] Snow RW, Guerra CA, Noor AM, Myint HY, Hay SI. The global distribution of clinical episodes of Plasmodium falciparum malaria. Nature 2005; 434(7030): 214-7.

[2] Menéndez C, Romagosa C, Ismail MR, et al. An autopsy study of maternal mortality in Mozambique: the contribution of infectious diseases. PLoS Med 2008; 5(2): e44.

[3] EA EP, Alves JG. The causes of death of hospitalized children in Angola. Trop Doct 2008; 38(1): 66-7.

[4] Taylor W, White N. Antimalarial drug toxicity: A review. Drug Saf 2004; 27(1): 25-61.

[5] Talisuna AO, Bloland P, D'Alessandro U. History, dynamics, and public health importance of malaria parasite resistance. Clin $\mathrm{Mi}$ crobiol Rev 2004; 17(1): 235-54.

[6] Amino R, Thiberge S, Martin B, et al. Quantitative imaging of Plasmodium transmission from mosquito to mammal. Nat Med 2006; 12(2): 220-4.

[7] Sturm A, Amino R, van de Sand C, et al. Manipulation of host hepatocytes by the malaria parasite for delivery into liver sinusoids. Science 2006; 313(5791): 1287-90.

[8] Cowman AF, Crabb BS. Invasion of red blood cells by malaria parasites. Cell 2006; 124(4): 755-66. 
[9] Przyborski JM, Lanzer M. Protein transport and trafficking in Plasmodium falciparum-infected erythrocytes. Parasitology 2005; 130(Pt 4): 373-88.

[10] Cooke BM, Lingelbach K, Bannister LH, Tilley L. Protein trafficking in Plasmodium falciparum-infected red blood cells. Trends Parasitol 2004; 20(12): 581-9.

[11] Pevet P, Agez L, Bothorel B, et al. Melatonin in the multioscillatory mammalian circadian world. Chronobiol Int 2006; 23(12): 39-51.

[12] Hotta CT, Gazarini ML, Beraldo FH, et al. Calcium-dependent modulation by melatonin of the circadian rhythm in malarial parasites. Nat Cell Biol 2000; 2(7): 466-8.

[13] Hotta CT, Markus RP, Garcia CR. Melatonin and N-acetylserotonin cross the red blood cell membrane and evoke calcium mobilization in malarial parasites. Braz J Med Biol Res 2003; 36(11): 1583-7.

[14] Varotti FP, Beraldo FH, Gazarini ML, Garcia CR. Plasmodium falciparum malaria parasites display a THG-sensitive $\mathrm{Ca} 2+$ pool. Cell Calcium 2003; 33(2): 137-44.

[15] Beraldo FH, Almeida FM, da Silva AM, Garcia CR. Cyclic AMP and calcium interplay as second messengers in melatonindependent regulation of Plasmodium falciparum cell cycle. J Cell Biol 2005; 170(4): 551-7.

[16] Beraldo FH, Garcia CR. Products of tryptophan catabolism induce $\mathrm{Ca} 2+$ release and modulate the cell cycle of Plasmodium falciparum malaria parasites. J Pineal Res 2005; 39(3): 224-30.

[17] Garcia CR. Calcium homeostasis and signaling in the blood-stage malaria parasite. Parasitol Today 1999; 15(12): 488-91.

[18] Gazarini ML, Garcia CR. The malaria parasite mitochondrion senses cytosolic Ca2+ fluctuations. Biochem Biophys Res Commun 2004; 321(1): 138-44.

[19] Gazarini ML, Thomas AP, Pozzan T, Garcia CR. Calcium signaling in a low calcium environment: how the intracellular malaria parasite solves the problem. J Cell Biol 2003; 161(1): 103-10.

[20] Passos AP, Garcia CR. Inositol 1,4,5-trisphosphate induced Ca2+ release from chloroquine-sensitive and -insensitive intracellular stores in the intraerythrocytic stage of the malaria parasite $P$. chabaudi. Biochem Biophys Res Commun 1998; 245(1): 155-60.

[21] Passos AP, Garcia CR. Characterization of $\mathrm{Ca} 2+$ transport activity associated with a non-mitochondrial calcium pool in the rodent malaria parasite $P$. chabaudi. Biochem Mol Biol Int 1997; 42(5): 91925.

[22] Lew VL, Tiffert T. Is invasion efficiency in malaria controlled by pre-invasion events? Trends Parasitol 2007; 23(10): 481-4.

[23] Nagamune K, Sibley LD. Comparative genomic and phylogenetic analyses of calcium ATPases and calcium-regulated proteins in the apicomplexa. Mol Biol Evol 2006; 23(8): 1613-27.

[24] Vaid A, Sharma P. PfPKB, a Protein Kinase B-like Enzyme from Plasmodium falciparum: II. Identification of calcium/calmodulin as its upstream activator and dissection of a novel signaling pathway. J Biol Chem 2006; 281(37): 27126-33.
[25] Doerig C, Billker O, Pratt D, Endicott J. Protein kinases as targets for antimalarial intervention: Kinomics, structure-based design, transmission-blockade, and targeting host cell enzymes. Biochim Biophys Acta 2005; 1754(1-2): 132-50.

[26] Doerig C, Meijer L. Antimalarial drug discovery: targeting protein kinases. Expert Opin Ther Targets 2007; 11(3): 279-90.

[27] Ward P, Equinet L, Packer J, Doerig C. Protein kinases of the human malaria parasite Plasmodium falciparum: the kinome of a divergent eukaryote. BMC Genomics 2004; 5(1): 79.

[28] Drew ME, Banerjee R, Uffman EW, Gilbertson S, Rosenthal PJ, Goldberg DE. Plasmodium food vacuole plasmepsins are activated by falcipains. J Biol Chem 2008

[29] Doerig C. Protein kinases as targets for anti-parasitic chemotherapy. Biochim Biophys Acta 2004; 1697(1-2): 155-68.

[30] Rosenthal PJ. Antimalarial drug discovery: old and new approaches. J Exp Biol 2003; 206(Pt 21): 3735-44.

[31] Cambie G, Caillard V, Beaute-Lafitte A, Ginsburg H, Chabaud A, Landau I. Chronotherapy of malaria: identification of drugsensitive stage of parasite and timing of drug delivery for improved therapy. Ann Parasitol Hum Comp 1991; 66(1): 14-21.

[32] Landau I, Lepers JP, Ringwald P, Rabarison P, Ginsburg H, Chabaud A. Chronotherapy of malaria: improved efficacy of timed chloroquine treatment of patients with Plasmodium falciparum infections. Trans R Soc Trop Med Hyg 1992; 86(4): 374-5.

[33] Levi F, Focan C, Karaboue A, et al. Implications of circadian clocks for the rhythmic delivery of cancer therapeutics. Adv Drug Deliv Rev 2007; 59(9-10): 1015-35.

[34] Portaluppi F, Lemmer B. Chronobiology and chronotherapy of ischemic heart disease. Adv Drug Deliv Rev 2007; 59(9-10): 95265 .

[35] Gorbacheva VY, Kondratov RV, Zhang R, et al. Circadian sensitivity to the chemotherapeutic agent cyclophosphamide depends on the functional status of the CLOCK/BMAL1 transactivation complex. Proc Natl Acad Sci USA 2005; 102(9): 3407-12.

[36] Buttgereit F, Doering G, Schaeffler A, et al. Efficacy of modifiedrelease versus standard prednisone to reduce duration of morning stiffness of the joints in rheumatoid arthritis (CAPRA-1): a doubleblind, randomised controlled trial. Lancet 2008; 371(9608): 205-14.

[37] Vanecek J. Cellular mechanisms of melatonin action. Physiol Rev 1998; 78(3): 687-721.

[38] Mathes AM, Wolf B, Rensing H. Melatonin receptor antagonist luzindole is a powerful radical scavenger in vitro. J Pineal Res 2008.

[39] AlKadi HO. Antimalarial drug toxicity: a review. Chemotherapy 2007; 53(6): 385-91.

[40] Garcia CRS, Azevedo MF, Wundelich G, Budu A, Young JA, Bannister L. Plasmodium in the post genomic era:new insights into the molecular cell biology of malaria parasites. Inter Rev Cell Mol Biol 2008; 266(3): 85-156.

() Bagnaresi et al.; Licensee Bentham Open.

This is an open access article distributed under the terms of the Creative Commons Attribution License (http://creativecommons.org/licenses/by/2.5/), which permits unrestrictive use, distribution, and reproduction in any medium, provided the original work is properly cited. 